\title{
Preoperative Management of Cataract Surgery Candidates: An Evaluation of Their Perception and Preferences
}

\author{
Evgenia Kanonidou*, Vasileios Konidaris, Christina Kanonidou, Leonidas Papazisis
}

Department of Ophthalmology, General Hospital of Veria, Veria, Greece.

Email: *evkanon@hotmail.com

Received January $4^{\text {th }}, 2013$; revised February $5^{\text {th }}, 2013$; accepted March $4^{\text {th }}, 2013$

Copyright (C) 2013 Evgenia Kanonidou et al. This is an open access article distributed under the Creative Commons Attribution License, which permits unrestricted use, distribution, and reproduction in any medium, provided the original work is properly cited.

\begin{abstract}
Purpose: To assess the primary visual disability in patients with cataract and to evaluate their preference regarding the visual outcome after surgery. Materials and Methods: 120 patients (66 males, mean age 76.3 years, mean best corrected visual acuity 5.2/10 binocularly) participated. Perception regarding the primary visual disability related to cataract and preference of visual outcome after surgery were assessed by a questionnaire. All study procedures adhered to the principles outlined in the Declaration of Helsinki for research involving human subjects, and all participants gave written informed consent before their participation. Results: 74 patients (61.6\%) had difficulty in distant vision, 5 (4.2\%) in near vision, 17 (14.2\%) mentioned blurred vision, 14 (11.7\%) difficulty in driving especially at night, 7 (5.8\%) complained about monocular diplopia and 3 (2.5\%) about anisometropia. All mentioned that they preferred to obtain clear distant and near vision after cataract surgery. Conclusions: There was an interesting variety in visual disability related to cataract. The difficulty in distant vision was the primary visual deficit in the majority of the patients and the preference for clear distant and near vision was the desired postoperative visual outcome.
\end{abstract}

Keywords: Cataract; Visual Outcome; Visual Disability; Quality of Life

\section{Introduction}

Cataract is one of the commonest causes of vision loss and the commonest cause of reversible loss of useful vision worldwide [1]. It is defined as the loss of transparency of the natural lens of the eye, usually due to the ageing process $[1,2]$. The only treatment is surgery, which has become the most frequent performed surgery in industrialized countries [2]. As the trend towards smaller incisions and shorter operating time continues, less sedation and anesthesia are required [3]. Topical anesthesia and intracameral anesthesia are the standard for cooperative patients [4-6]. Snellen chart visual acuity is the standard procedure to measure the preoperative visual acuity and thereby the indication of cataract surgery and the postoperative outcome. However, the disability of a patient with cataract goes beyond the loss of visual acuity, as decreased visual function is associated with poor quality of life and general functioning living activities. The aim of this study was to evaluate the primary visual dis-

\footnotetext{
*Corresponding author.
}

ability in patients with cataract, their perception regarding the postoperative visual outcome and their preferences regarding the preoperative management.

\section{Methods}

120 patients (66 males) with mean age 76.3 years old and mean best corrected visual acuity 5.2/10 binocularly participated in the study. All the patients were recruited through the cataract clinic of the Department of Ophthalmology of General Hospital of Veria, Veria, Greece for a time period of one year. All had a history of visually significant cataract for their daily activities for at least six months and suffered from no other ocular comorbidity. All the participants were of a basic educational level and occupied themselves with agriculture. Their perception regarding the primary visual disability related to cataract, their preference with respect to the visual outcome after cataract surgery as well as their attitudes related to the preoperative management was assessed by means of a simple questionnaire. All study 
procedures adhered to the principles outlined in the Declaration of Helsinki for research involving human subjects, and all participants gave written informed consent before their participation.

\section{Results}

74 patients $(61.6 \%)$ had difficulty in distant vision, 5 (4.2\%) in near vision, 17 (14.2\%) mentioned blurred vision as the primary visual disability associated with cataract while 14 patients $(11.7 \%)$ had difficulty driving especially at night. Moreover, 7 patients (5.8\%) complained about monocular diplopia while 3 (2.5\%) about anisometropia (Figure 1). All the participants mentioned that despite their preoperative refractive status preferred to obtain clear vision for both distant and near after cataract surgery. All the patients wanted the preoperative general screening tests to be undertaken in the hospital compared to private practice. 78 (65\%) preferred to return home the day of the surgery while 42 (35\%) would felt more secure with a day residency in the hospital. 99 (82.5\%) wanted the anesthesia to be provided by eye drops instillation while 21 (17.5\%) with injection. 78 (65\%) preferred the surgery to be performed by a male surgeon, 6 (5\%) by female, while the rest (30\%) did not show any particular preference. 12 (10\%) patients preferred to be transferred to the theatre with a patient bed, 40 (33\%) with a wheel-chair, while the rest (57\%) on foot. The desired refractive outcome after cataract surgery was clear vision for both distance and near in all patients. All preferred to be examined every week after the surgery and for a month's period of time. All were absolutely satisfied by their preoperative management and the only reason for disappointment was the crowded wards.

\section{Discussion}

Our study provides important documentation about the primary visual disability in patients with cataract and their preference regarding the visual outcome after cata-

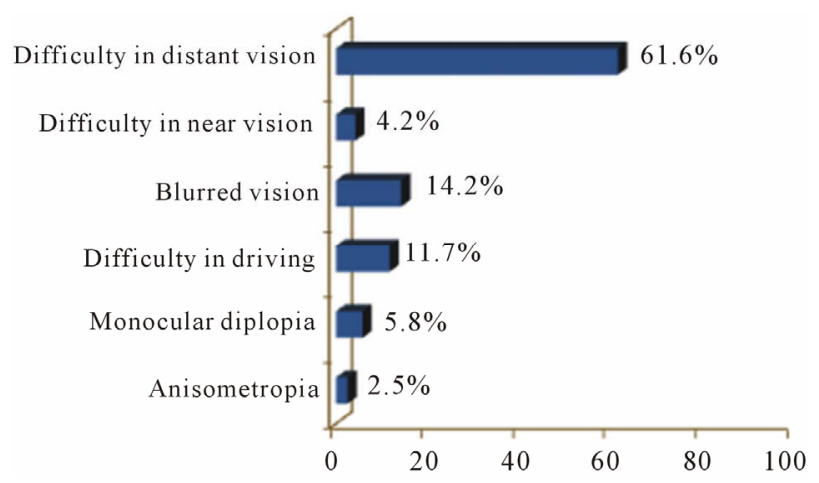

Figure 1. Primary visual disability in patients with cataract who participated in our investigation. ract surgery. It was interesting to observe the variety in visual disability related to cataract, with difficulty in distant vision being the primary visual deficit in the majority of the patients, as well as their preference for clear vision for both distant and near as the desired postoperative visual outcome. Recent studies suggest that poor vision has a greater impact on patients' lives than was previously thought, comparable with major medical conditions such as stroke [7]. Moreover, the benefits of cataract surgery on visual function have been demonstrated in several investigations [8-10], suggesting that cataract surgery improves functioning in everyday life with respect to vision dependent activities.

Understanding the spectrum of disability associated with visual impairment from cataracts can help clinicians improve their approach to treatment and rehabilitation of these patients. Additionally, in our study, it was interesting to note that there was reluctance in the majority of the patients for the surgery to be performed by a female surgeon. This is probably related to elderly patients' cautiousness regarding female surgical skills in the rural area of Greek territory.

\section{Conclusion}

In conclusion, in this article, perception of 120 patients regarding the primary visual disability related to cataract and preference of visual outcome after surgery were assessed by a questionnaire to assess the primary visual disability in patients with cataract and to evaluate their preference regarding the visual outcome after surgery. As patients have widely differing visual demands, it is vital to take these into account when considering surgery in order that surgery induced improvements in visual acuity be translated by considerable gains in real life activities, emotional and social life components.

\section{REFERENCES}

[1] T. Kohnen, M. Baumeister, D. Kook, O. K. Klaproth and C. Ohrloff, "Cataract Surgery with Implantation of an Artificial Lens,” Dtsches Arzteblatt International, Vol. 106, No. 43, 2009, pp. 695-702.

[2] J. Sturmer, "Cataracts-Trend and New Developments," Thereutische Umschau, Vol. 66, No, 3, 2009, pp. 167171.

[3] P. A. Asbell, I. Dualan, J. Mindel, D. Brocks, M. Ahmad and S. Epstein, “Age-Related Cataract,” Lancet, Vol. 365, No. 9459, 2005, pp. 599-609.

[4] J. Naor and A. R. Slomovic, "Anesthesia Modalities for Cataract Surgery," Current Opinion in Ophthalmology, Vol. 11, No. 1, 2000, pp. 7-11. doi:10.1097/00055735-200002000-00003

[5] A. S. Crandall, "Anesthesia Modalities for Cataract Surgery," Current Opinion in Ophthalmology, Vol. 12, No. 1, 2001, pp. 9-11. doi:10.1097/00055735-200102000-00003 
[6] M. J. Oakley, D. Ellis and D. Mullins, "Evolution of Cataract Surgery Anesthesia,” Journal of Cataract \& Refractive Surgery, Vol. 28, No. 12, 2002, p. 2244. doi:10.1016/S0886-3350(02)01903-X

[7] E. M. Chia, J. J. Wang, E. Rochtchina, W. Smith, R. R. Cumming and P. Mitchell, "Impact of Bilateral Visual Impairment on Health-Related Quality of Life: The Blue Mountains Eye Study,” Investigative Ophthalmology \& Visual Science, Vol. 45, No. 1, 2004, pp. 71-76. doi:10.1167/iovs.03-0661

[8] C. S. Gray, G. Karimova, A. J. Hildreth, L. Crabtree, D. Allen and J. E. O’Connell, "Recovery of Visual and Functional Disability Following Cataract Surgery in Older
People: Sunderland Cataract Study," Journal of Cataract \& Refractive Surgery, Vol. 32, No. 1, 2006, pp. 60-66. doi:10.1016/j.jcrs.2005.07.040

[9] P. Desai, A. Reidy, D. C. Minassian, G. Vafidis and J. Bolger, "Gains from Cataract Surgery: Visual Function and Quality of Life,” British Journal of Ophthalmology, Vol. 80, No. 10, 1996, pp. 868-873. doi:10.1136/bjo.80.10.868

[10] M. Abrahamsson, B. Carlsson, M. Tornqvist, B. Sterner and J. Sjostrand, "Changes of Visual Function and Visual Ability in Daily Life Following Cataract Surgery,” Acta Ophthalmologica Scandinavica, Vol. 74, No. 1, 1996, pp. 69-73. doi:10.1111/j.1600-0420.1996.tb00686.x 